\title{
LOS CAMBIOS LEGISLATIVOS EN LOS TERRITORIOS OCUPADOS POR ISRAEL DESPUÉS DE $1967^{*}$
}

\author{
YANIZA GIRALDO RESTREPO** \\ Hugo FERnANDo GuERRERo SIERRA***
}

\begin{abstract}
RESUMEN: Después de la Guerra de los Seis Días en 1967, el Estado de Israel ocupó Gaza, Cisjordania y Jerusalén Este. Tras su ocupación, se establece un gobierno militar que tiene la potestad de hacer cambios legislativos en virtud de mantener el orden y la seguridad en la región. Sin embargo, la autorización del gobierno de Israel de construir asentamientos judíos dentro del territorio palestino, ha repercutido a nivel social y económico en la región. La hipótesis de este artículo es que estas modificaciones no siempre han favorecido a la población civil, porque crean una legislación dual: una para los habitantes de la región palestina y otra, para la población residente en los asentamientos judíos.
\end{abstract}

PalabRas CLAVE: Cambios legislativos - Territorios - Ocupación Palestina - Israel.

\section{LEGISLATIVE CHANGES IN THE OCCUPIED TERRITORIES BY ISRAEL AFTER 1967}

ABSTRACT: After Six-Day War in 1967, the State of Israel occupied Gaza, the West Bank and East Jerusalem. Following its occupation, a military government that has the power to make legislative changes under maintains order and security in the region is established. However, the authorization of the government of Israel to build Jewish settlements in

\footnotetext{
* $\quad$ Este trabajo ha sido realizado dentro del marco del proyecto: "Un análisis hermenéuticoempírico de las condiciones para el conocimiento, interpretación y aplicación del Derecho Constitucional frente al Derecho Internacional”; proyecto de investigación financiado por la Universidad de San Buenaventura Cali (Colombia).

Fecha de recepción: 9 de febrero de 2015.

Fecha de aceptación: 12 de enero de 2016.

** Doctora en Derecho, Universidad Carlos III de Madrid (España). Máster en Derecho Público, Universidad Carlos III de Madrid (España). Docente-Investigadora de la Universidad de San Buenaventura Cali (Colombia). Correo electrónico: yagire@gmail.com

*** Doctor en Relaciones Internacionales, Universidad Complutense de Madrid (EsPaña). Abogado, Universidad Nacional de Colombia (Colombia) Actualmente Docente-Investigador y Director del Grupo de Investigación en Política y Relaciones Internacionales en la Universidad de La Salle (Colombia). Correo electrónico: hguerreros25@gmail.com
} 
the Palestinian territory has impacted social and economic status in the region. The hypothesis of this paper is that these changes have not always favored the civilian population because they create a dual legislation: one for residents of the Palestinian region and another one for the resident population in Jewish settlements.

KEYWORDS: Legislative changes - territories - occupation - Palestine - Israel.

Sumario: Introducción. 1) La Ocupación de Palestina por Israel. 2) Cambios legislativos: el derecho aplicable en los Territorios Ocupados. 3) Órdenes del Gobierno Militar. 4) Creación de tribunales militares. 5) Cambios por razones de seguridad. 6) Recaudo de impuestos. 7) La aplicación del derecho humanitario y el papel del Tribunal Supremo de Israel. 8) Modificaciones geográficas a raiz de los asentamientos judios. 9) La construcción del muro en palestina. Conclusiones.

\section{INTRODUCCIÓN}

Tras la Guerra de los Seis Días, el Estado de Israel ocupó Cisjordania, Gaza y Jerusalén Este. Posterior a la ocupación, se realizaron cambios políticos, económicos, militares y gubernamentales en los Territorios Ocupados (en adelante, TO). En este sentido, es importante anotar que en la actualidad hay una disputa sobre el estatus de Jerusalén ${ }^{1}$ porque Israel la considera parte del Estado y capital del mismo; actuación contraria con las disposiciones de una parte de la Comunidad Internacional que la ve como una ocupación ilegal ${ }^{2}$. En este artículo se analizarán los cambios legislativos llevados a cabo en los TO hasta el ańo 2005, donde Israel se retira de manera unilateral de Gaza, dejando la administración general a la Autoridad Palestina. Se analiza el conflicto que surge a raíz de la ocupación, las trasformaciones que se realizan en los ańos de ocupación, y las justificaciones del Estado de Israel desde el paradigma de la seguridad nacional. Se destaca el papel del Tribunal Supremo de Israel cuando conoce de los abusos realizados por el gobierno militar establecido en los TO, y cómo en algunas ocasiones aprueba las violaciones a los derechos humanos a raíz de la ocupación.

\footnotetext{
1 Ley Básica. Jerusalén, Capital de Israel. 30 de julio de 1980. Disponible en, https://www. knesset.gov.il/laws/special/eng/basic10_eng.htm

2 The situation in the Middle East, AG Res. 32/20 noviembre 25 de 1977.
} 


\section{1) LA OCUPACIÓN DE PALESTINA POR ISRAEL}

La Guerra de los Seis Días empezó el 5 de junio de 1967, como ataque preventivo de Israel contra Egipto, este último ayudado por Siria y Jordania $^{3}$. Según la versión israelí este ataque fue en respuesta al creciente rearme y concentración de tropas de la península del Sinaí, que amenazaban directamente su territorio ${ }^{4}$. Después de este ataque Israel amplió sus fronteras más allá de Palestina, ocupando Cisjordania, la Franja de Gaza, Jerusalén Este, el desierto del Sinaí y los Altos del Golán sirios; a pesar que la postura oficial es la administración de los territorios lo cual no constituye en ningún momento anexión. Posterior del cese al fuego, el Consejo de Seguridad aprobó la resolución 237 (1967) en la cual se pedía a Israel que garantizara la protección, seguridad y bienestar de los habitantes de las zonas donde se habían producido los enfrentamientos militares y que se diera las condiciones para el regreso de las personas desplazadas. Se instó a los gobiernos interesados cumplir con los principios humanitarios que protegían a las personas civiles en conflicto, establecidos en el IV Convenio de Ginebra de 1949. El Estado de Israel, ha controlado los territorios ocupados desde 1967, realizando cambios legislativos y demográficos que han afectado los derechos humanos de las personas bajo ocupación, lo que ha generado un atraso en la región. Israel, ante la falta de acuerdo con las autoridades palestinas, se retiró de manera unilateral de Gaza en 2005.

\section{2) CAMbios Legislativos: El DeRECHO APliCABle EN LOS TERRITORIOS OCUPADOS}

Después de la guerra de 1967 y posterior a la ocupación de Cisjordania, Gaza ${ }^{5}$ y Jerusalén Este, el Gobierno Militar establecido en los TO adaptó normas del derecho Jordano e Israelí en Cisjordania, y del egipcio e israelí en Gaza ${ }^{6}$. Esta administración militar presenta dos características importantes. Primero, que se establece un Gobierno Militar en los TO

3 Fernández Gómez, Manuel; Peco Yeste, Miguel (2003) El Conflicto Palestino-Israeli. Madrid: Instituto de Estudios Internacionales y Europeos "Francisco Vitoria”, p. 61.

4 Fort Navarro, Albert; Martínez IbáÑez, Enrique (2002) El conflicto Palestino-Israelí: un recorrido histórico para comprender el presente. Valencia: Diálogo, p. 86.

5 En relación con Gaza, se establecieron cambios en la región hasta el año 2005, donde Israel se retira de manera unilateral. Véase, Agreed documents on movement and access from and to Gaza (2005) Disponible en:

http://www.mfa.gov.il/mfa/foreignpolicy/peace/mfadocuments/pages/agreed $\% 20$ documents $\% 20$ on $\% 20$ movement $\% 20$ and $\% 20$ access $\% 20$ from $\% 20$ and $\% 20$ to $\% 20$ gaza $\% 2015$ nov-2005.aspx [Fecha de visita: 1 de septiembre de 2015].

6 Shawan, Usahma (2003) Public Administration in Palestine: past and present. Oxford: University Press of America, p. 54. 
distinto, que aplica normas contrarias al marco jurídico del Derecho de Ocupación. Segundo, la ocupación militar ha sido prolongada, lo que ha generado varias preguntas por ejemplo, si han sido necesarios los cambios físicos en la región, la composición demográfica, la estructura institucional o el estatuto de los territorios palestinos y los TO desde 1967. Tras la ocupación, el TSI resuelve de las disputas derivadas de las actividades militares aplicando el derecho internacional, los principios del derecho público de Israel y el derecho vigente previo a la ocupación.

La incorporación del derecho internacional en el ordenamiento jurídico israelí estará determinada de acuerdo al tipo de normativa internacional, si es consuetudinario o convencional. La doctrina desarrollada a través de los años por el TSI establece la costumbre internacional parte del sistema jurídico israelí y por tanto, su incorporación es automática y no tiene que ser confirmado mediante un acto legislativo por el Knesset ${ }^{7}$. No obstante, cuando se presenta una duda respecto de la costumbre o difiere respecto de la normativa nacional, prevalece esta última ${ }^{8}$. Así pues, en la aplicación del DIH y el Derecho internacional de los derechos humanos hay una posición diferente entre el Gobierno israelí y el TSI. El primero considera que el DIH aplica a los TO porque es el ordenamiento más idóneo en situaciones de guerra, toda vez que las medidas serán tomadas en aras de proteger la población y la seguridad de la región, también una medida temporal que terminará en el momento de la resolución del conflicto, mientras que la jurisprudencia del TSI ha incluido diferentes instrumentos internacionales relacionados con los derechos humanos ${ }^{9}$, complementarios a las demás normas aplicadas. En ocasiones este se aparta de las políticas del Poder Ejecutivo que tiene como medida la seguridad por encima de los intereses de la población en los TO. El DIH y el Derecho internacional de los derechos humanos se complementan en la práctica, en especial para la protección de las personas frente a las acciones militares en un conflicto ${ }^{10}$.

Los tribunales israelíes reconocen el poder del ejecutivo para concluir tratados internacionales, y en la práctica se observa cómo el TSI reconoce

$7 \quad$ Shetreet, Shimon (1986) "Limmits and promises of International norms and procedure for the Protection of Human Rights". En Goldstein, Stephen: Israeli Reports to the International 12th Congress of law. Jerusalem: Harry Sacher Institute for Legislative Research and Comparative Law, pp. 48-49.

8 HCJ 69/81 "Abu Aita et al. v. The Regional Commander of Judea and Samaria”. Disponible en: http://elyon1.court.gov.il/files_eng/81/690/000/Z01/81000690.z01.pdf [fecha de visita 3 de diciembre de 2015] párr. 53 (c) p. 146.

pp. 42-43. Disponible en, http://elyon1.court.gov.il/files_eng/81/690/000/Z01/81000690. z01.pdf

9 Shetreet (1986) 34-35.

10 Droege, Cordula (2007) "The Interplay between international humanitarian law and international human rights law in situations of armed conflict”. Israel Law Review, Vol. 40, N², p. 312. 
la autonomía del Knesset para concluir y ratificar los tratados sin necesidad que estos tengan una revisión previa por parte del poder legislativo. Este cumple un papel importante en el conflicto palestino-israelí porque se encarga de dictar sentencias relacionadas con las obligaciones del Estado de Israel dentro de los TO, suspendiendo o confirmando las actividades que se llevan a cabo en la región ocupada ${ }^{11}$.

El derecho internacional establece que la autoridad legislativa del área ocupada es transferida al Gobierno Militar del Estado ocupante ${ }^{12}$, con el objetivo de asegurar el orden y garantizar la administración del territorio ocupado. Estas medidas de ninguna manera pueden ir en detrimento del desarrollo del territorio ocupado ${ }^{13}$. Sin embargo, en el caso de los TO los cambios que ha realizado el Gobierno Militar no han sido solamente para beneficiar a la población palestina, sino teniendo en cuenta las necesidades de la población de los asentamientos judíos. Un ejemplo de esos cambios que no benefician a la población palestina son las construcciones de viviendas para personas israelíes en territorio palestino, que buscan solo favorecer al Estado de Israel, pero no para el mejoramiento de las condiciones de vida de la población. Por tanto, estas modificaciones constituyen una violación efectiva del artículo 27 del IV Convenio de Ginebra relativo a la protección de personas civiles en tiempos de guerra; y que sin duda son un obstáculo para lograr una paz duradera en la región. En este caso, se ha desconocido la obligación del Estado de Israel como potencia ocupante, de analizar todos los cambios en la región, y decidir si son necesarios para la protección del derecho a la propiedad de la población palestina, toda vez que el artículo 33 del mismo Convenio de Ginebra, prohíbe todas las medidas de represalia contra las personas protegidas y sus bienes ${ }^{14}$.

El caso de los asentamientos judíos ha sido justificado por el Gobierno Militar por ser una medida necesaria para restablecer, conservar el orden público y la seguridad en la región ${ }^{15}$. Sin embargo, la confiscación y apropiación territorial no constituye una medida legal y necesaria para el control del orden público en la región palestina, sino que por el contrario, genera mayores problemas por el enfrentamiento entre la población palestina y la de los asentamientos judíos. Estas funciones y poderes del Gobierno Militar no están definidos en el IV Convenio de Ginebra, pues

11 Lapidoth, Ruth (1990) "International Law within the Israel Legal System". Israel Law Review, Vol. 24, p. 451.

12 Rubinstein, A. (1988) “The changing status of the "territories” (West Bank and Gaza). From scrow to legal mongrel”". Tel Aviv University Studies in Law, Vol. 8, p. 72.

Art. 27, IV Convención de Ginebra de 1949.

Resolución 465 del Consejo de Seguridad de la ONU (1980), párrafo 5.

El término autoridad militar no está especificado en el IV Convenio de Ginebra, a diferencia del Convenio de La Haya, 18 de octubre de 1907, que sí refleja las disposiciones básicas sobre la ocupación beligerante. Ver, Sección III, art. 43. 
en este se mencionan las obligaciones de la potencia ocupante en la protección de las personas frente a los efectos de la guerra, estatuto y trato a las personas protegidas, todo lo relacionado con los territorios ocupados, sin definir qué hacer en situaciones de ocupación prolongada, en qué momento debe terminar la ocupación, quedando con esto en un vacío jurídico los alcances del poder ocupante.

Entonces, el derecho internacional solo prevé la responsabilidad que tiene el gobierno ocupante ${ }^{16}$ frente al territorio ocupado, sin hacer mención a los derechos y obligaciones del gobierno militar que se establezca. Con lo cual, eso supone un problema pues la organización del gobierno militar no la regula el derecho internacional, sino que es el propio Estado ocupante quien debe delegar estas funciones en el territorio ocupado, de conformidad con la normativa internacional. La potestad otorgada a un Estado ocupante no deja de ser parcializada porque serán estos quienes tienen la autonomía de limitar o no las acciones del Gobierno Militar designado en la región ocupada.

\section{3) ORdenes Del Gobierno Militar}

Posterior a la ocupación israelí, el Gobierno Militar emitió las Ordenes No.1 y 3 del 7 de junio de $1967^{17}$ que transfirieron las competencias legales y administrativas en los $\mathrm{TO}^{18}$. Estos cambios en las nuevas políticas de ocupación trajeron consigo mayor autoridad a los comandantes militares del área, sobre los gobiernos municipales palestinos, influyendo en casi todos los aspectos de la vida de los palestinos por las regulaciones militares ${ }^{19}$, entre otros: la libertad de movimiento, la entrada y salida, las licencias de conducción supeditadas a la autorización militar. Los palestinos han estado sometidos a las decisiones y órdenes emitidas por el Gobierno Militar, sin que se haga un control de legitimidad de las mismas. El problema de estas órdenes es que están reguladas desde el derecho internacional, que permite al ocupante intervenir en todos los aspectos de la vida ${ }^{20}$ de la población ocupada. En consecuencia, el IV Convenio de

16 Los poderes de la potencia ocupante siguen siendo un debate en la actualidad y han generado diferentes puntos de vista opuestos en relación con los deberes del ocupante de asegurar y restaurar la vida civil y las limitaciones legales que tienen. Ver, Benvenisti, Eyall (1993) The international law of occupation. New Jersey: Princeton Universal Press, pp. 9-10.

17 Para ver la reproducción en ingles de las órdenes 1 y 3 ver, Singer (1982) 266-267.

18 SHAWAN (2003) 45-46.

19 Drori, Moshe (1977) "Second Municipal Elections in Judea and Samaria under Israel Administration: Legislative Changes”. Israel Law Review, Vol. 12, pp. 527-528.

20 Declaration concerning the Laws and Customs of War. Brussels, 27 August, 1874, que dispone: Art. 2. The authority of the legitimate Power being suspended and having in fact passed into the hands of the occupants, the latter shall take all the measures in his power to restore and ensure, as far as possible, public order and safety. Disponible en: https://www.icrc.org/ihl/INTRO/135 
Ginebra solo regula la situación de las personas que se encuentran bajo ocupación, las competencias y derechos que tiene la potencia ocupante, sin tener en cuenta qué se debe hacer cuando la ocupación es prologada.

Ante la ocupación y en cumplimiento de la normativa internacional en escenarios de ocupación, en Palestina se estableció que las decisiones tomadas por los militares se pueden apelar a los tribunales militares creados por el Estado de Israel, y serán estos mismos quienes deciden la confirmación o rechazo de la petición ${ }^{21}$. Estos cambios legislativos aunque son permitidos por el derecho internacional posibilitan abusos de autoridad y, en definitiva, crea un sistema jurídico que beneficia al ocupante. Entre los problemas que se han generado en Palestina se puede destacar la autoridad que tiene el Gobierno Militar sobre las empresas de los TO, al autorizar o prohibir a una persona fundar una empresa o ser contratado por cualquier proyecto sin haber obtenido el permiso especial de las autoridades militares ${ }^{22}$. Esto ha sido criticado porque los empresarios están sometidos a la respuesta de los militares que pueden denegar en la mayoría de los casos la creación de una empresa por cuestiones de seguridad. Lo que genera más pobreza y subdesarrollo en la región.

El problema jurídico que se presenta es que el derecho de ocupación beligerante no siempre se aplica en los TO, porque el Gobierno Militar está sujeto a las disposiciones del Ministro de Defensa israelí. Es decir, no hay igualdad en las decisiones que se toman por parte de los militares porque estos dependen de la política establecida por el Estado de Israel. Lo que ha generado un sistema jurídico dual que beneficia al Estado de Israel en su política de asentamientos, realizando cambios legislativos no por la necesidad de la región ocupada sino para su propio beneficio. De manera que el Gobierno Militar no autoriza la creación de empresas teniendo en cuenta los derechos de la población palestina, sino los intereses del Estado de Israel; esta estructura ha permitido a los militares convertirse en actores políticos dentro del conflicto ${ }^{23}$.

La dualidad le sirve a Israel para actuar y definirse dentro de su territorio como un Estado democrático, pero al mismo tiempo, tener un

21 Artículo 66 -III. Tribunales Competentes. IV Convenio de Ginebra relativo a la protección debida de personas civiles en tiempos de guerra, 1949.

La Potencia ocupante podrá someter a los acusados, en caso de infracción de las disposiciones penales por ella promulgadas en virtud del párrafo segundo del artículo 64, a sus tribunales militares, no políticos y legitimamente constituidos, a condición de que éstos funcionen en el país ocupado. Los tribunales de apelación funcionarán preferentemente en el país ocupado.

Comité contra la Tortura. CAT/C/ISR/CO/4 23 de junio de 2009, párrafo (11). [en línea] http://www.acnur.org/t3/fileadmin/Documentos/BDL/2010/7944.pdf?view=1 [fecha consulta. 1 septiembre de 2015].

22 Shenadeh, Raja (1985) Occupier's Law: Israel and the West Bank. $1^{\circ}$ Edition. Washington: Institute for Palestine Studies, p. 119.

23 Grinberg, Lev (2008) "El 'régimen dual' en Israel desde 1967". Araucaria, Revista Iberoamericana de Filosofia, Politica y Humanidades, $\mathrm{N}^{\circ}$ 19, Primer semestre, p. 132. 
comportamiento diferente frente a la población palestina, quienes no tienen los mismos derechos ni posibilidades, es decir, con ciudadanía negada a la cual se define como externa y temporal 24 . Los comandantes militares regionales en los TO representan al Gobierno Militar y son funcionarios operativos de la política gubernamental, por esto no siempre aplican el derecho de ocupación sino órdenes ministeriales que hacen cambios sin tener en cuenta las necesidades de la región ${ }^{25}$. Estos tienen la capacidad de tomar medidas directas que permitan detener las amenazas externas de los enemigos, grupos terroristas que busquen desestabilizar la región ${ }^{26}$.

El Gobierno de Israel, a través de las oficinas militares, legisla sobre los asuntos generales de la población ocupada palestina, sin hacer revisiones parlamentarias de dichas disposiciones, con la justificación que está actuando bajo las disposiciones internacionales y, por tanto, no debe existir un cuestionamiento legal de dichos actos 27 . Esta situación de ocupación prolongada sin duda ha carecido de legitimidad y justificación, porque los cambios realizados en los TO no han beneficiado a la población palestina, ni han permitido su desarrollo económico y social. Entonces, lo que se busca con estos cambios es una seguridad transicional que propicie la reconstrucción de las instituciones de la región y que permita normalizar la vida de la población, hasta que se pueda llegar a la independencia del territorio ocupado. Esto permite subsanar los vacíos de poder y es la pieza fundamental para el paso de la guerra a una paz duradera ${ }^{28}$.

No obstante, hay un vacío legal en el derecho internacional porque en escenarios de ocupación prolongada, no hay una normativa que especifique lo permitido o prohibido en este caso. Se presenta pues la disyuntiva de la aplicación del derecho internacional humanitario o el derecho internacional de los derechos humanos, pues el derecho internacional ha otorgado amplios poderes a la potencia ocupante ${ }^{29}$. La función del derecho internacional humanitario es en primera medida proteger al ser humano de los sufrimientos que se derivan de situaciones de conflicto armado. Es decir, no importa qué tipo de conflicto se refiera, los individuos poseen derechos bajo el derecho internacional humanitario y por tanto, sin importar el tipo de calificación de un conflicto, serán protegidas las víctimas de un conflicto armado sin hacer distinción en si pertenece al bando enemigo. Así, las normas humanitarias son universales, sin tener en cuenta si

Grinberg (2008) 124 .

Rubinstein (1988) 73.

Jacoby, Tami Amanda; SAsley, Brent E. (2002) Redefining Security in the Middle East.

Canada: Manchester University Press, p. 31.

Rubinstein (1988) 73.

28 Voorhoeve, Joris (2007) From War to the Rule of Law: Peacebuilding after violent conflicts. Amsterdam: University Press Amsterdam, p. 54.

29 Dinstein, Yoram (2009) The International Law of belligerent occupation. Cambridge: University Press, pp. 116-117. 
serán aplicadas a una comunidad que comparte los mismos valores culturales o geográficos, e incluso aplica más allá de las fronteras de batalla. El derecho internacional humanitario está basado en un principio fundamental que se establece en el artículo 1 común a los cuatro Convenios de Ginebra y es su cumplimiento en todas las circunstancias, aplicadas a todas las partes en conflicto ${ }^{30}$ en situación de ocupación de corta o larga duración, porque el objeto del mismo es la protección del individuo.

En el caso de la ocupación militar israelí, es importante hacer una distinción entre la ocupación militar de corta y larga duración, porque las disposiciones aunque son las mismas no tienen igual efectividad y pueden ser interpretadas de diferente forma. Por tanto, es necesario tomar medidas diferentes que busquen mejorar la situación económica y social de la población ocupada. Las acciones legislativas que no son adecuadas y se toman en una situación de ocupación militar de corta duración podrían ser validas en situaciones de larga ocupación ${ }^{31}$, siempre y cuando sean necesarios para el beneficio de la población local y no representen mayores cambios institucionales en la región ${ }^{32}$. Estos cambios legislativos realizados a lo largo de la ocupación podrían ser aceptados en los TO, si el gobierno de Israel no legitimara y apoyara la creación y existencia de los asentamientos judíos, porque esto resta autoridad al gobierno militar y genera dudas en cuanto al beneficio de los cambios en la región ocupada. Hasta que Israel no retire los asentamientos judíos, estos constituyen una extensión territorial de la jurisdicción del Estado de Israel.

En consecuencia, el cambio sustancial del Derecho existente en la región ocupada antes de 1967, donde se ha establecido una legislación diferente para los habitantes árabes y judíos, ha generado los denominados enclaves $^{33}$. En los enclaves judíos en territorio palestino se han realizado cambios legislativos que no tienen en cuenta el derecho internacional sino el derecho israelí, violando así el derecho del pueblo palestino a su autodeterminación, a tener un Estado independiente y no supeditado a las decisiones de la potencia ocupante de Israel ${ }^{34}$. Esta legislación dual conlleva a la limitación de la autoridad que tiene el Consejo Regional Árabe y los representantes de las ciudades árabes, transferidas desde los Acuerdos de Camp David donde se dispone el paso de un estado de ocupación a uno de paz, y donde se pueda crear las condiciones para facilitar

\footnotetext{
30 Thürer, D. (2011) International Humanitarian Law: A Unique Regime. Collected Courses of the Hague Academy of International Law, Vol. 338. Brill Nijhoff: Hague Academy of International Law, pp. 51-52.

Rubinstein (1988) 76.

Dinstein (2009) 119-120.

Azoulay, Ariella; Ophir, Adi (2012) The one state-condition: Occupation and Democracy in Israel/Palestine. Standford California: Standford University Press, p. 90.

34 Boyle, Francis Anthony (2003) Palestine, Palestinians and International Law. Michigan: Clarity Press, p. 58.
} 
esa transición ${ }^{35}$ lo que sin duda no tienen, y el problema de estos cambios es que no hay una autoridad neutral que pueda sancionar las acciones del Gobierno Militar, pues el derecho internacional otorga potestad a este para crear tribunales en los TO, para que resuelvan los conflictos que se presenten en la región. Esto es algo que no deja de ser parcializado, pues los tribunales son conformados por militares israelíes que están más dispuestos a los intereses del Estado de Israel, que a las necesidades de la población palestina.

\section{4) CREACión de TRIBUNALES MiLitares}

El Gobierno Militar establecido en los TO tiene la potestad para conocer de los delitos penales cometidos y se aplicará la legislación penal vigente en el momento de la ocupación, a menos que la Potencia ocupante considere que esa legislación es una amenaza para su seguridad (artículos 64 Convenio G.). Asimismo, tiene la autoridad para crear tribunales militares, no políticos y legitimamente constituidos, con jurisdicción sobre la población palestina ${ }^{36}$. Solo en estos casos se permite que los civiles puedan ser juzgados por un sistema legal militar por delitos cometidos en la región ocupada ${ }^{37}$; los acusados responderán en caso de infracciones siempre y cuando no sean políticos, aunque no dispone nada respecto a la creación de tribunales de apelación. En los TO se creó un tribunal de apelaciones solo hasta el año $1989^{38}$, lo que le valió a Israel la crítica internacional puesto que constituía una violación a la Declaración Universal de Derechos Humanos ${ }^{39}$ y al Pacto Internacional de Derechos Civiles y Políticos de $1966^{40}$.

En los TO es posible presentar apelaciones por acciones administrativas de: reclamaciones oficiales, órdenes de internamiento y detención. Si esa petición es inadmitida por una omisión administrativa o por un acto arbitrario es posible recurrir ante el Tribunal Supremo de Israel (en adelante, TSI) como última instancia ${ }^{41}$. El TSI no tiene competencia según

\footnotetext{
35 Azoulay/Ophir (2012) 94.

36 Artículo 66, IV Convenio de Ginebra.

37 Artículos 64 y 66 de la IV Convención de Ginebra.

38 Peleg, Ilan (1995) Human rights in the West Bank and Gaza. Legacy and Politics. $1^{\circ}$ edition. New York: Syracuse University Press, p. 77.

39 Artículo 11(1). Toda persona acusada de delito tiene derecho a que se presuma su inocencia mientras no se pruebe su culpabilidad, conforme a la ley y en juicio público en el que se le hayan asegurado todas las garantías necesarias para su defensa.

40 Israel firmó el Pacto, el 3 de octubre de 1966. Véase, Articulo 14(5). Toda persona declarada culpable de un delito tendrá derecho a que el fallo condenatorio y la pena que se le haya impuesto sean sometidos a un Tribunal Superior, conforme a lo prescrito por la ley.

41 Shamgar, Meir (1982) "Legal Concepts and Problems of the Israeli Military GovernmentThe Initial Stage". En Shamgar, Meir (editor): Military government in the territories administered by Israel 1967-1980: the legal aspects. Jerusalem: Alpha Press, p. 51.
} 
el derecho internacional para conocer las disputas entre el gobierno militar y la población palestina de los TO. Sin embargo, desde 1967 ha recibido las demandas y recursos presentados a causa de la ocupación militar israelí jugando un papel importante en la resolución de las disputas que se presentan a causa de la ocupación. De acuerdo con los precedentes legales, los tribunales municipales en los periodos de las dos Guerras Mundiales denegaron las peticiones presentadas ante estos por los habitantes de los territorios bajo administración militar ${ }^{42}$. Este activismo del TSI ha sido recibido con agrado por la población palestina porque es la última instancia a la que pueden recurrir, para frenar las órdenes emitidas por el gobierno militar en Palestina. No obstante, no deja de ser una situación anormal porque el TSI pertenece a un Estado ocupante y solo se encarga de confirmar o denegar las acciones militares, pero en ningún caso entra a cuestionar la ocupación.

En los TO se han presentado problemas con el funcionamiento de los tribunales militares por la participación del Comandante militar ${ }^{43}$ en los procesos de apelaciones, porque este hace las veces de legislador, tiene facultades para nombrar funcionarios, jueces $\operatorname{locales}^{44} \mathrm{y}$ disminuir las penas o anular las condenas ${ }^{45}$; algo que sin duda permite la parcialización y no garantiza un proceso justo. El IV Convenio de Ginebra y el Convenio de La Haya otorgan suficientes poderes a la potencia ocupante en materia judicial, por ello es importante la presencia de un Tribunal de Apelaciones independiente de la autoridad militar en la región ocupada, que resuelva las controversias que se generan a causa de la ocupación. La actividad del Gobierno Militar de Israel ha sido muy amplia y ha permitido establecer cambios en materia política, administrativa, que no siempre benefician a la población palestina ${ }^{46}$. En consecuencia, no es posible hablar de independencia judicial en los TO porque los jueces dependen del poder ejecutivo israelí ${ }^{47}$.

La independencia judicial de los jueces militares y fiscales es limitada porque su actividad judicial hace parte de las Fuerzas de Defensa Israelí (en adelante FDI ${ }^{48}$. Esa relación permanente entre el gobierno militar y

\footnotetext{
42 Shamgar, Meir (1971) "The Observance of International Law in the Administered Territories". Israel Yearbook on Human Rights, Vol. 1, p. 273.

43 Singer, Joel (1982) "The establishment of a civil administration in the areas administered by Israel”. Israel Yearbook on Human Rights, Vol. 12, pp. 273-276.

44 SHEHADEH (1985) 69.

45 B"TSELEM (1990) The Military Judicial System in the West Bank-Follow up Report. Disponible en, http://www.btselem.org/search/google_cse_adv/the\%20military\%20judicial\%20 system $\% 20$ in $\% 20$ the $\% 20$ west $\% 20$ bank-\%20follow\%20up\%20report\%201990

46 Benvenisti, Meron (1984) The West Bank Database Project: A survey of Israel's policies. Washington: American Enterprise Institute for Public Policy Research, p. 14.

47 Peleg (1995) 75.

48 Peleg (1995) 80.
} 
quienes hacen parte del poder judicial son un problema para llevar a cabo un juicio justo e imparcial ${ }^{49}$. Las leyes aplicadas por los tribunales en los TO serán las del procedimiento penal israelí. Esta ley permite la detención de sospechosos hasta por cuatro días sin comparecer ante un juez por delitos contra la seguridad nacional ${ }^{50}$.

En los TO se aceptó la creación tribunales palestinos que tienen jurisdicción territorial para juzgar cualquier infracción que se cometa, esto se consiguió desde los Acuerdos de Oslo51. Estos tribunales palestinos pueden conocer los casos penales de ciudadanos israelíes residentes en los TO en materia criminal. No existe una ley u orden militar que diga lo contrario, sin embargo, esto no se da en la práctica porque la población de los asentamientos judíos no está dispuesta a someterse a esta jurisdicción ${ }^{52}$. La facultad que tiene el Gobierno Militar de establecer tribunales en la región ocupada, no ha favorecido la autonomía y desarrollo de la región palestina. Por el contrario, se han promulgado leyes que otorgan mayores poderes al gobierno ocupante, pero que en realidad no son necesarias para el progreso y mantenimiento de la seguridad en la región ${ }^{53}$.

\section{5) CAMBIOS POR RAZONES DE SEGURIDAD}

Al no existir prohibición legal para que la potencia ocupante cambie las normas penales vigentes en el momento de la ocupación, en aras de la seguridad y mantenimiento de la administración de justicia ${ }^{54}$, la función de los tribunales militares ha sido la de revisar la legalidad y validez de estos actos. A su vez, los oficiales israelíes aplican el derecho administrativo israelí dependiendo de la situación, a pesar que lo dispuesto por el derecho internacional es que para suspender las leyes vigentes al momento de la ocupación, estas deben ir acorde con las restricciones prescritas en el artículo 64 del IV Convenio de Ginebra y el artículo 43 del Convenio de

49 Amnistía Internacional (1991) Israel and the occupied territories. the military justice system, in the Occupied Territories: detention, interrogation and trial procedures. New York, Amnesty International, p. 17.

50 CAT/C/ISR/CO/4, 23 de junio de 2009. Disponible en: http://docstore.ohchr.org/SelfServices/FilesHandler.ashx?enc=6QkG1d\%2fPPRiCAqhKb7yhsmEKqNhdzbzr4kqou1ZPE7\% 2fYp3qNk2Xa\%2fzyRKr\%2fdzPo1K8L\%2bY3c96KNU7RETHg\%2ff3PV1uFvvR5Md9dz 0tI\%2f3Lz4qwUmwleXHj9Hu0fZsmLsj

51 Véanse los compromisos establecidos en estos acuerdos: http://www.mfa.gov.il/mfa/foreignpolicy/peace/guide/pages/declaration $\% 20$ of\%20principles\%20-\%20main\%20points.aspx

52 Institute for Palestine Studies (1984) The Karp report: An Israeli government inquiry into settler violence against Palestinians on the West Bank. Washington: Institute for Palestine Studies, p. 52.

53 Drori, Moshe (1978) "The legal system in Judea and Samaria: a review of the previous decade with a glance of the future". Israel Yearbook on Human Rights, Vol. 8, p. 160.

54 Artículo 64 de la IV Convenio de Ginebra y el artículo 43 del Convenio de La Haya de 1907. 
La Haya. Así pues, que al aplicar el derecho administrativo israelí, y hacer cambios en la región, que no tienen justificación para el mantenimiento de la seguridad o el desarrollo de la población, se está incumpliendo con el derecho internacional humanitario aplicado en situaciones de ocupación.

Lo que hizo el Estado de Israel después de la ocupación en 1967, es dejar por escrito que el derecho aplicado por los tribunales militares en los TO sería el sistema jurídico en vigor, antes del establecimiento del Gobierno Militar; también las órdenes dictadas por estos en virtud de las necesidades locales. Esa relación entre el derecho local y las órdenes dictadas por la autoridad militar, se dejaron estipuladas en la Proclamación No 2, la cual ha sido determinada como marco constitucional a seguir dentro de la región ocupada ${ }^{55}$. Si hay discrepancia entre el derecho local y las órdenes militares, estas últimas prevalecen. Algo no se ha cumplido porque dependiendo de las necesidades del Gobierno Militar establecido en la región, se han ido realizando los cambios.

Por consiguiente, las decisiones tomadas en materia de seguridad en los TO dependen del gobierno israelí. En los TO se han llevado a cabo modificaciones a las leyes penales existentes, por necesidad de adecuar la normativa a la situación militar de la región. El Artículo 64 del IV Convenio de Ginebra establece que se pueden suspender las leyes penales por el ocupante cuando constituya una amenaza a la seguridad, para garantizar el orden y la administración; las leyes pueden ser suspendidas solo por el periodo de la ocupación. Estas obligaciones no han sido respetadas por el Gobierno Militar porque no se aplican las leyes civiles, administrativas o constitucionales existentes previamente a la ocupación ${ }^{56}$. La necesidad militar será el recurso utilizado para promulgar nueva legislación, otorgando amplios poderes al ocupante para hacer modificaciones ante cualquier peligro o amenaza a su seguridad ${ }^{57}$. Sin embargo, en aras de proteger la seguridad y mantener el bienestar de población palestina, será necesario tener en cuenta el cumplimiento de todos los tratados ratificados por Israel y lo dispuesto por el derecho internacional de los conflictos armados. En tanto, se deben tener en cuenta los derechos humanos que incluso en tiempos de guerra o en situaciones de emergencia no pueden ser derogados ${ }^{58}$. A pesar de que estos derechos humanos no se encuentren reconocidos en una sola Convención que especifique su aplicación en tiempo de guerra, se puede tomar de referencia el artículo 4(2) del Pacto Internacional de Derechos Civiles y Políticos de 1966, el Convenio Eu-

SHAMgar (1982) 53.

Dinstein (2009) 111.

Artículo 27 de la IV Convención de Ginebra de 1949.

Artículos 6, 7, 8 (párrafos 1 y 2), 11, 15, 16 y 18. Pacto Internacional de Derechos Civiles y Políticos de 1966. 
ropeo de Derechos Humanos de 1950 que estipula en el artículo 15(2) la protección de otros derechos humanos, y el Artículo 27(2) de la Convención Americana de Derechos Humanos.

A continuación, se explicarán los cambios realizados por el Gobierno Militar en materia tributaria en los TO, con la justificación de mejorar las condiciones de vida de la población palestina. Sin embargo, todos estos se desvirtúan a causa de la ocupación ilegal y el establecimiento de los asentamientos judíos en la región. Según la normativa internacional, estos impuestos no pueden ir en detrimento del desarrollo de la población civil y solo se justifican para el beneficio de la región.

\section{6) RECAUdO DE IMPUESTOS}

En los TO el Gobierno Militar controla todo lo relacionado con los impuestos como forma de mantener y mejorar los servicios públicos o el desarrollo económico en la región. Los cambios legislativos realizados en materia tributaria han sido cuestionados porque se acusa a Israel de beneficiar a la autoridad militar, y una forma de controlar a la población ocupada sin traer con esto cambios sustanciales en la calidad de vida de las personas.

El Gobierno Militar asumió el manejo de los impuestos en los TO en todo lo relacionado con: impuesto sobre la renta, de propiedad municipal, a los negocios, sobre bienes inmuebles rurales, a la propiedad de estructuras industriales. En especial, el impuesto de bienes inmuebles sobre todo en propiedades rurales se ha visto afectado en los años de ocupación ${ }^{59}$. En el derecho consuetudinario no existe nada relacionado con la prohibición de hacer modificaciones legislativas al momento de la ocupación. No se ha observado una práctica contraria al art. 49 del Convenio de La Haya, que permite al ocupante recaudar otras contribuciones diferentes a los impuestos previstos, siempre y cuando esto sea por la necesidad del ejército militar o en beneficio de la administración del territorio ocupado $^{60}$. Ahora bien, la potencia ocupante no necesariamente tiene que cobrar impuestos en el territorio ocupado, pero si lo hace está sometido a unas limitaciones para llevar a cabo este objetivo. Los principios a seguir en esta materia son regulados por el Convenio de La Haya y deben cumplirse en el momento de cobrar los impuestos al gobierno ocupado. Los gravámenes, cuotas o peajes recaudados por la potencia ocupada deberán cumplir con unas normas de evaluación ${ }^{61}$.

59 SABri, Nidal (1995) "The Effects of Taxes Imposed on the Population of the Occupied Palestinian Territories". Paper presented at the Seminar on Living Conditions of the Palestinian People. Vienna: Habitat.

60 HCJ, 69/81, párr. 53(c) p. 146.

61 Véase artículo 48 de la IV Convención de Ginebra. 
Sobre esta imposición fiscal no existe una regla definida, por eso Israel tomó de referencia las disposiciones legales del Convenio de La Haya, de donde el Gobierno Militar hace la interpretación normativa para el cobro de impuestos $^{62}$. Estos no deben ser recaudados para beneficiar a la potencia ocupante sino para ayudar al desarrollo de la región. A pesar de cobrar impuestos, sigue siendo una obligación del Estado ocupante asumir los gastos de la administración del territorio ocupado, de la misma manera que lo estaba haciendo el gobierno ocupado ${ }^{63}$. Solo después de cobrar y pagar los gastos que surgen de la administración de un territorio ocupado, el dinero sobrante puede utilizarse para el ejército de la ocupación ${ }^{64}$.

Si estos ingresos son insuficientes para cubrir todas las obligaciones de la administración o la población civil, el ocupante podría de manera legal modificar las tarifas para aumentar el recaudo. El método que aplicó Israel en principio fue el de transferencia de fondos de la Tesorería de Israel a los TO, y de manera gradual fue aumentando el recaudo a gran escala. El dinero adquirido fue utilizado para el desarrollo de la región y la creación de puestos de trabajo, que en el comienzo de la ocupación constituyó una importante cooperación económica entre las dos economías; favoreciendo el desarrollo de la agricultura y la producción industrial en los TO. Sin embargo, la calidad de vida de los TO se deterioró con el paso de los años por todos los enfrentamientos en la región. La ocupación, sumada a la destrucción de viviendas e instalaciones públicas, los toques de queda, las detenciones y, las ejecuciones extrajudiciales ha contribuido claramente al atraso de la región. El encargado de determinar la legalidad de incrementar los impuestos en los TO, es un Comité de Apelaciones creado por el Gobierno Militar, quienes deciden sobre la legalidad del aumento contributivo ${ }^{65}$. El cobro de impuestos ha sido cuestionado, pues se considera que no es en beneficio de la población palestina sino de Israel.

De conformidad con el derecho internacional, cuando se presentan dudas en relación con la creación de nuevos impuestos en territorios ocupados, será necesario hacer esto solo se hace en virtud de restablecer, conservar el orden público y la seguridad ${ }^{66}$. Contrario a esto, se incum-

62 De conformidad con el Tribunal Supremo de Israel, el artículo 43 puede ser visto como base para una nueva legislación fiscal, si la adopción de normas es necesaria para cumplir los objetivos del gobierno militar. Ver, HCJ 69/81, párr. 53(e) p. 146.

63 Playfair, Enma (1992) International law and the Administration of Occupied Territories. Oxford: Clarendon Press, pp. 350.

IV Convenio de Ginebra, articulo 49.

Playfair (1992) 293.

HCJ 168/91 "Murkos v. Minister of Defense et al.".

Se sostuvo que de conformidad con el art. 43 de las Regulaciones de La Haya, el Poder del Ocupante es proporcionar la seguridad de los habitantes de los T.O. lo que evita posibles 
plirá esta regla cuando no sea posible su cumplimiento por la autoridad militar $^{67}$. Con esta forma se limita el derecho de imponer nuevos impuestos y se permiten estos cambios si es absolutamente necesario. En el caso del Gobierno Militar en los TO, es difícil establecer según el derecho internacional qué cambios en realidad puede hacer. Las disposiciones internacionales le confieren mayor potestad al ocupante respecto a los cambios jurídicos del territorio, que restricciones a las medidas tomadas en la transformación del derecho existente en la región.

Roberts establece que en el marco del derecho internacional es legítimo el poder del ocupante, y los cambios que se realicen en búsqueda de las condiciones democráticas y la paz estatal de un territorio ocupado, armonizar los intereses humanitarias con las necesidades militares de los ocupantes, prevenir los cambios destructivos en el territorio ocupado y preservar los derechos a futuro de soberanía, preservar la disciplina militar entre las fuerzas ocupantes que generen incontrolado ejercicio del poder $^{68}$, pero no por ello es excluyente la aplicación del Derecho Internacional de los Derechos Humanos, porque ofrece a los habitantes alternativas para la protección de sus derechos frente a las acciones del poder ocupante ${ }^{69}$.

En los TO se han presentado abusos de autoridad a través de la creación de nuevos impuestos en la Franja de Gaza, siendo criticado por los empresarios porque consideran que están en contravención con el Convenio de La Haya. En consecuencia, las personas afectadas presentaron una demanda ante el TSI para que determinase la legalidad de estas imposiciones fiscales. El objeto de la demanda se centró en la legalidad de la potencia ocupante para imponer nuevos impuestos en la región ${ }^{70}$, asimismo, la responsabilidad del ocupante de garantizar su propia seguridad y la de la población ocupada. La sentencia estuvo a favor de las medidas de financiación por medio de nuevos impuestos, pero en la decisión no dice nada sobre la creación de impuestos o las situaciones que pueden generar dicha necesidad, ni tampoco los requisitos a cumplir para la promulgación de estos.

El TSI hace una interpretación del caso teniendo en cuenta que la costumbre internacional no prohíbe estas acciones en los territorios bajo

discriminaciones hacia la población. (La sentencia se puede encontrar en inglés en Israel Yearbook on Human Rights, Vol. 23, 1993, p. 339).

67 Sobre la autoridad militar en territorio hostil del estado, véase el artículo 43, del IV Convenio de Ginebra.

68 Roberts, Adam (1990) "Prolonged military occupation: the Israeli-occupied territories since 1967". The American Journal International Law, Vol. 84, p. 46.

69 Roberts, Adam (2006) "Transformative military occupation: applying the laws of ward and human rights". The American Journal International Law, Vol. 100, p. 620.

70 HCJ 69/81, p. 1. 
ocupación, siempre y cuando no dañen la economía de los territorios ${ }^{71}$. En sentencia no se presentan argumentos suficientes que demuestren la necesidad de estos cambios tributarios, como algo necesario para mejorar la vida de la población palestina. No dice nada sobre las repercusiones que pueda tener para la población palestina la recaudación de impuestos desde el inicio de la ocupación hasta la actualidad. A su vez, no responde a la petición realizada por los demandantes frente a los escasos beneficios que ha tenido la imposición de nuevos impuestos a la población ocupada, teniendo en cuenta que la mayoría de los civiles de los TO se encuentran repartidos entre la Franja de Gaza y en Cisjordania. Estos se encuentran en campos de refugiados ${ }^{72}$ en condiciones muy precarias y dependientes de la ayuda internacional ${ }^{73}$. Con lo cual, la recaudación de nuevos impuestos no ha servido para mejorar las condiciones de vida de la población palestina ocupada.

El TSI explica la creación de nuevos impuestos en los TO haciendo un análisis de las normas internacionales vinculantes para Israel, pero no entra a cuestionar la necesidad y utilidad de estos para el Gobierno Militar y la población civil. En la jurisprudencia sobre la ocupación militar, no dice si las disposiciones u ordenanzas tomadas por las autoridades militares han sido legítimas. En este caso el TSI no ha tenido un papel decisivo e importante, para mejorar las condiciones de la población civil, de las decisiones abusivas e ilegales que pueden ser establecidas a causa de la ocupación militar. Es importante apuntar que aunque haya una ocupación prolongada que eventualmente conlleve a dudas sobre la aplicación del derecho internacional, esto no afecta la validez de las leyes, en este caso específico el Convenio de La Haya en materia de impuestos ${ }^{74}$.

En definitiva, en materia de tributación bajo ocupación beligerante las leyes aplicables son ambiguas y deficientes, pues no disponen qué hacer en entornos de ocupación prolongada y, en la mayoría de los casos, otorgan amplia potestad al ocupante para decidir sobre la población civil. La tendencia a no preservar el Derecho vigente en la región se puede observar en las decisiones del TSI, y en especial las relacionadas con las decisiones del Gobierno Militar y el Consejo Superior de Planificación

\footnotetext{
71 HCJ 69/81, párr. 53(c) (d).

72 El problema de los refugiados palestinos se originó fundamentalmente en los desplazamientos de población motivados por la ocupación israelí de territorios palestinos, durante las guerras de 1946 y 1948. De acuerdo con la Organización UNRWA, los descendientes de estos refugiados también tienen los mismos derechos para la Agencia de Refugiados que atiende a aquellos que viven en cinco zonas: Franja Gaza, Cisjordania, Jordania, Líbano y Siria. Según las estadísticas, el número de palestinos refugiados es más de 5 millones. Disponible en: http://www.unrwa.org/palestine-refugees

Playfair (1992) 373.

74 En el IV Convenio de Ginebra no se estipula qué hacer en materia de impuestos.
} 
de carreteras, que unen los territorios con centros urbanos de Israel $^{75}$; los cuales han llevado a cabo transformaciones geográficas que benefician la población israelí que se encuentra en los TO, creando un sistema jurídico dual, con preferencia de la población de los asentamientos judíos.

\section{7) La aplicación del Derecho Humanitario Y EL PAPEL Del TRIBUNAL SUPREMO DE ISRAEL}

Con el paso del tiempo y con los cambios legislativos dentro de la región ocupada por Israel, surgen varias preguntas sobre cuál es el Derecho aplicable en una ocupación prolongada, y sobre cómo resolver el conflicto que surge entre la población originaria y quienes ejercen el poder. Todo esto sin duda fue una de las causas para el surgimiento de la Intifada en Gaza y en Cisjordania en 1987, por lo que se hace necesario un análisis detallado de la normativa aplicada por el ocupante, si es efectiva o por el contrario conlleva a un obstáculo en el desarrollo político, económico y legislativo en la región ${ }^{76}$. Aunque no se puede decir que exista una Convención especial o tratado único que regule las leyes de la guerra y la ocupación militar, sí hay diferentes instrumentos internacionales que pueden ser tomados de referencia para determinar los poderes del ocupante y los límites de sus acciones ${ }^{77}$.

Por esto, es importante supervisar las acciones de las fuerzas militares para reducir los problemas entre los ocupantes y la población ocupada, lo que ayudará al respeto y protección de la población civil ${ }^{78}$. La posición oficial del gobierno israelí respecto a la obligación de cumplir con las normas internacionales en los TO, es en algunos sentidos ambivalente y confusa. Para empezar, el Estado no reconoce la situación de ocupación sino que la denomina de "territorios administrados", lo que implica en primer lugar que Israel no reconoce su soberanía sobre Palestina, y segundo, el compromiso de retirarse del área de control. El gobierno de Israel ${ }^{79}$ no ha tenido una posición clara respecto al derecho aplicable en los TO. En el caso del IV Convenio de Ginebra, argumenta que no aplica en los TO porque están fuera de su jurisdicción y su aplicación implicaría el recono-

75 HCJ 393/82 "Jamait Askan et al. v. IDF Commander of Judea and Samaria". Disponible en: http://www.hamoked.org/Document.aspx?dID=160 [fecha de visita: 3 de diciembre de 2015].

76 RoBERTs (1990) 45.

77 Koutroulis, Vaios (2002) "La aplicación del derecho internacional humanitario y el derecho internacional de los derechos humanos en situaciones de ocupación prolongada: ¡solo cuestión de tiempo?”. International Review of the Red Cross, No 885, pp. 6-7

78 RoBerts (1990) 6.

79 Shamgar (1982) 366-368. 
cimiento de la soberanía de Jordania en la región ${ }^{80}$, razones que no aclara de fondo. Esta explicación no tiene mucho sentido porque Israel podría aplicar el IV Convenio de Ginebra, sin una aceptación implícita de la soberanía mediante una reserva a esta materia de controversia.

Israel utiliza los términos de 'territorios administrados' en vez de 'territorios ocupados' y establece que cuando exista duda sobre la aplicabilidad de jure de un convenio puede ser utilizado de facto; a diferencia del Convenio de La Haya de 1907, que es aplicado tanto de jure cómo de facto, y que aunque Israel no lo haya ratificado e incorporado en su derecho interno, es interpretado en el caso de los TO por ser parte de la costumbre internacional $^{81}$. Shamgar, sostuvo que aunque no hay una regla del derecho internacional que establezca que el IV Convenio de Ginebra aplica para todo conflicto armado, su aplicación puede ser de facto de acuerdo con las disposiciones humanitarias. De ahí se interpreta la obligación del Gobierno Militar de cumplir con las normas de ocupación beligerante, asimismo lo dispuesto por el TSI ${ }^{82}$. El ocupante no adquiere la soberanía sobre el territorio por la ocupación militar de hecho, pero sí obtiene el derecho de ejercitar la autoridad militar sobre este, mas no sin restricciones. La administración es el objetivo legítimo y necesario después de la ocupación para garantizar la seguridad del ejército militar, aunque los derechos del ocupante no sean absolutos. Las obligaciones y restricciones están codificadas en la costumbre internacional y en las convenciones internacionales que son catalogadas de costumbre internacional ${ }^{83}$.

Como prueba de la dualidad en el sistema jurídico utilizado en los TO, son los casos presentados al TSI donde reconoce el cumplimiento de las normas del IV Convenio de Ginebra, pero siempre y cuando los procesos no sean relacionados con los asentamientos judíos; pues en este caso rechaza su aplicación. Esta posición del TSI es aceptada y defendida por Rubinstein, cuando manifiesta que la aplicación del presente Convenio por los tribunales puede ser cuestionada. Sin embargo, lo que no es discutible es la incorporación de este dentro de la normativa interna de Israel porque esto es un acto legislativo: "Indeed, in parliamentary regimes like

80 Hay que recordar que Jordania ocupó ilegalmente Cisjordania en 1948. La Franja de Gaza fue ocupada en el mismo año por Egipto, así que según Israel la aplicación del IV Convenio de Ginebra implicaría el reconocimiento de soberanía de estos Estados que nunca se retiraron oficialmente de estos territorios. El IV Convenio de Ginebra fue ratificado por Israel, el 6 de julio de 1951 y Jordania es parte del mismo desde el 29 de mayo de 1951. Allan, Gerson (1973) "Trustee-Occupant: The Legal Status of Israel's Presence in the West Bank". Harvard International Law Journal, Vol. 14, pp. 9-10.

81 Cohen, Esther (1985) Human Rights in the Israel-Occupied Territories 1967-1982. Manchester: Manchester University Press, p. 43.

82 SHAMGAR (1982) 44.

83 SHAMGAR (1982) 28. 
those of England and Israel, only the legislature has the power to change the internal law of the State" 84 .

Así, el IV Convenio de Ginebra es vinculante para Israel y podría ser aplicado dentro de los TO sin ningún problema si estos territorios fueran parte de Israel. Estos argumentos presentados son insatisfactorios y desconocen los precedentes para la interpretación del derecho internacional humanitario, que incluye el derecho de la ocupación y su aplicación. El artículo 2 común a los Cuatro Convenios de Ginebra, dispone que las potencias en conflicto tendrán que aplicarlo ya sea en tiempo de paz, en caso de guerra declarada o de cualquier otro conflicto armado que surja entre dos o varias de las Altas Partes Contratantes, aunque una de ellas no haya reconocido el estado de guerra.

En esta misma línea, el IV Convenio de Ginebra se aplicará también en todos los casos de ocupación total o parcial del territorio de una Alta Parte Contratante, aunque tal ocupación no encuentre resistencia militar. En este caso una parte de Palestina ${ }^{85}$ se encuentra bajo ocupación militar, y además, ha obtenido el reconocimiento de Estado en la ONU, el IV Convenio dispone que las Potencias que son partes, estén obligadas a cumplir con las disposiciones en sus relaciones recíprocas; la cual busca asegurar que las personas bajo ocupación sean tratadas con humanidad ${ }^{86}$. Las leyes de ocupación beligerante intentan evitar los cambios abruptos en los TO y los abusos de poder que puede tener la fuerza militar ${ }^{87}$.

En situaciones de ocupación prolongada es importante la relación entre el derecho de los conflictos armados y la normativa de los derechos humanos, que no pierden vigencia en el tiempo. La interrelación entre las leyes de derechos humanos y la del derecho de los conflictos armados, no excluye la aplicabilidad del IV Convenio de Ginebra, sino que sirve también de complemento a las provisiones, adicionando otras disposiciones en materias de protección de derechos humanos. La normativa de derechos humanos es aplicable a todas las personas sin importar el lugar que se encuentren, ni su condición. Se podrían aplicar las normas consuetudinarias presentes en la Declaración Universal de Derechos Humanos y el Derecho Internacional de los Derechos Humanos como suplemento del Derecho Internacional de ocupación beligerante, aunque el Estado no sea parte, Puesto que estos instrumentos permiten protección a la población civil durante la ocupación prolongada ${ }^{88}$.

\footnotetext{
84 Rubinstein (1988) 66.

85 Mediante una declaración formulada el 7 de julio de 1982, Palestina expresó un compromiso unilateral de ser parte del IV Convenio de Ginebra.

86 Playfair (1992) 27.

87 Arai-TAKaHAshi, Yutaka (2009) The Law of occupation: continuity and change of international Humanitarian Law, and its interaction with international Human Rights Law. California: Martinus Nijhoff, p. 327. Cohen (1985) 9.
} 
La dificultad que quizás pueda surgir en el momento de aplicar estas disposiciones legales, es el compromiso de las organizaciones internacionales encargadas de la implementación y cumplimiento de obligaciones ${ }^{89}$. Las quejas de violaciones a los derechos humanos por las partes en conflicto, son usadas de justificación por los Estados para no cumplir con el Derecho Internacional de los Derechos Humanos. El Estado de Israel en ocasiones ha reconocido que en los TO se puede aplicar el Pacto Internacional de Derechos Civiles y Políticos y el Pacto Internacional de Derechos Económicos, Sociales y Culturales. Sin embargo, su tesis general es que el derecho humanitario es el derecho aplicable a situaciones de conflicto, porque los tratados de derechos humanos protegen a la población en tiempos de paz ${ }^{90}$.

El TSI juega un papel importante dentro del conflicto palestinoisraelí, en las decisiones que toma frente a las actuaciones del Gobierno Militar, al revisar los cambios establecidos en los $\mathrm{TO}^{91}$; lo que se ha incrementado a través de los años de ocupación. Se puede observar un aumento en las decisiones que limitan y cuestionan las actividades gubernamentales en la región. No obstante, este activismo ha sido cuestionado por los juristas israelíes, porque tienen la idea que la jurisdicción de este es conferida solamente a los territorios donde Israel tiene soberanía. Así las cosas, el derecho israelí se aplicará solo en el Este de Jerusalén y en los altos del Golán a través de los actos legislativos ${ }^{92}$. Se critica su actividad porque la ocupación no ha terminado, e Israel no ostenta la soberanía dentro de los TO.

En relación con las acciones militares en los TO, la posición del Estado ha sido que los actos del gobierno militar serán considerados "actos de Estado", de manera que no pueden ser sometidos a revisión judicial ${ }^{93}$. De acuerdo a la tradición jurídica en lo relacionado con la ocupación militar, se puede observar que un tribunal de la potencia ocupante no asume el poder de revisión judicial de las acciones del Gobierno Militar. Sin embargo, es importante que el TSI conozca las demandas presentadas por la población palestina a causa de los abusos de los militares, y mejorar así

Cohen (1985) 8.

Véase la posición jurídica del Israel en, A/ES-10/248, Anexo I.

Karayanni, Michael M. (2014). "Access to Justice Ascends to International Civil Litigation: The Case of Palestinian Plaintiffs before Israeli Courts". Civil Justice Quarterly, Vol. 33, N ${ }^{\circ}$ 1, pp. 48-52.

92 Shetreet, Shimon (1994) Justice in Israel: A Study of the Israeli Judiciary. Boston: Martinus Nijhoff Publishers, p. 489 .

93 Benvenisti, Eyal (1997) "Judicial Review of Administrative Action in the Territories Occupied in 1967”. En Itzhak, Zamir; Zysblat, Allen: Public Law in Israel. Oxford: Clarendon Press, p. 374. 
la protección de los derechos civiles en la región ${ }^{94}$. Sin esta posibilidad, la población estaría sometida siempre a las acciones y decisiones del Gobierno Militar. Esto sin duda ayuda a garantizar la protección de los derechos civiles y políticos, alterados a causa de la ocupación ${ }^{95}$.

Esta política seguida por el TSI restringe el poder de los comandantes militares y tropas de la región ocupada, ayudando a generar más responsabilidad de estos en el momento de tomar decisiones que vayan en contra del derecho internacional. No obstante, el papel del este solo es de conocer las demandas presentadas por los palestinos, pero nunca cuestiona la política de los asentamientos judíos, ni tampoco la ocupación. Este fundamenta su jurisdicción en la región ocupada a través de una explicación teórica: las peticiones presentadas por los palestinos son aceptadas en virtud de que el Gobierno Militar es una fuerza pública del Estado de Israel, que cumple una función legal. Por tanto, el TSI tiene jurisdicción para considerar si estas acciones son legales o ilegales a la luz del derecho internacional.

Ahora bien, la función que cumple el TSI en los TO no es fácil y de hecho puede ser modificada porque la jurisdicción de este para conocer las demandas de la población palestina puede ser restringida por el Gobierno de Israel, pues el consentimiento gubernamental es un consenso general $^{96}$ que de igual manera podría ser modificado en cualquier momento por el Knesset (Parlamento de Israel). Hasta la fecha la jurisprudencia de los TO versa sobre la revisión del poder militar en los cambios legislativos o de seguridad, aplicando dos fuentes del derecho: la costumbre internacional y el derecho administrativo israelíi ${ }^{97}$; algo que en principio no ha sido contrario con la política estatal. Esta es quizás una razón por la cual el TSI ha tenido un papel preponderante en la ocupación militar.

No es fácil ser juez o parte, y se puede decir que el TSI ha tenido cierto grado de independencia en el momento de tomar decisiones que afectan las actuaciones militares en los $\mathrm{TO}^{98}$. Se destaca por ejemplo, el caso Jamait Askan ${ }^{99}$, donde el juez Barak sostuvo que las reglas de ocupación beligerante son de obligatorio cumplimiento sin necesidad de

\footnotetext{
94 En este caso se podría hacer un análisis del artículo 64 de la Convención de Ginebra que dispone la creación de tribunales militares dentro de los territorios ocupados, para sustentar la competencia del TSI ya que en este artículo no estipula una prohibición en la revisión de las sentencias de los tribunales militares o las decisiones de los comandantes militares en la región. En este mismo sentido, los actos legislativos del comandante militar y sus órganos executivos.

95 Cohen, Esther (1985-1986) "Justice for Occupied Territory? The Israeli High Court of Justice Paradigm”. Columbia Journal Transnational Law, Vol. 24, p. 480. HCJ 393/82, p. 372.

Zamir, Itzhak; Zysblat, Allen (I996) Public Law in Israel. Oxford: Clarendon Press, p. 407. BAR-YAakov, Nissim (1990) "The Applicability of the Law of war to Judea and Samaria (The West Bank) and to the Gaza Strip". Israel Law Review, Vol. 24, p. 495. HCJ 393/82, párr.10.
} 
contar con la autorización gubernamental. No obstante, en relación con la aplicación de la Convención de La Haya en los TO, el TSI ha tenido una posición inequívoca porque esta es reconocida parte de la costumbre internacional y por tanto, hace parte del derecho interno de Israel $^{100}$. En las decisiones solo analiza el procedimiento seguido por el Gobierno Militar pero no entra a decidir de fondo la legalidad de las acciones. El Gobierno Militar tiene suficiente poder para actuar sin que el TSI tenga una influencia o intervención importante en ese ejercicio discrecional. En el tema de los asentamientos judíos no se ha pronunciado y su papel entonces ha sido el de legitimar o deslegitimar las actividades militares y los cambios establecidos en la región, sin cuestionar de fondo las transformaciones geográficas y jurídicas de los mismos. Sería importante que el TSI tuviera una posición firme frente a las decisiones militares analizando no solo la proporcionalidad de las actuaciones y el cumplimiento del derecho internacional, sino la legalidad de las medidas tomadas. Lo que sin duda contribuiría a mejorar las condiciones de vida de la población civil.

A continuación, se hará un análisis de los cambios demográficos realizados por Israel, al autorizar la construcción de asentamientos judíos, y que sin duda han sido decisivos para el Gobierno Militar al momento de justificar los cambios legales realizados en la región ocupada.

\section{8) MODIFICACIONES GEOGRÁFICAS A RAÍZ DE LOS ASENTAMIENTOS JUDÍOS}

La adquisición de tierras y los cambios geográficos en la región de los TO, hacen parte de las modificaciones realizadas por el Gobierno Militar. Así, la autoridad municipal encargada de la planificación de la tierra se redujo, prohibiendo la construcción y ubicación de viviendas incluso dentro o fuera de los límites municipales de cualquier ciudad palestina. Esta medida permitió el fomento de los planes de asentamientos judíos en lugares donde reside la población palestina, que Yiftachel ha denominado la conformación de una nueva identidad judía-sionista nacional étnica, que facilita el crecimiento económico de Israel y judaización de Palestina ${ }^{101}$.

Estas órdenes para la transformación demográfica de los TO permitieron el avance en la política de los asentamientos ilegales, obstaculizaron el desarrollo de la región, y no han ayudado para garantizar las condicio-

100 Rubinstein, Amnon (1996) The Constitutional Law of the State of Israel. 5a edition. Tel Aviv: Shoken, pp. 262-266. ; HCJ 785/87 "Abd Al Nasser Al Azis v. Commander of IDF forces in the West Bank". Disponible en:http://hamoked.org/items/160_eng.pdf [fecha de visita 3 de diciembre de 2015].

101 Yiftachel, Oren (1997) “Israel society and jewish-palestinian reconciliation: 'Ethnocracy' and its territorial contradictions". The Middle East Journal, Vol. 51, N 4, Autumn, pp. 506507. 
nes de vida de la población palestina. Las medidas han sido justificadas por la autoridad militar como necesarias para el mantenimiento de las condiciones sociales y el beneficio para la población. Sin embargo, el TSI se pronunció al respecto, asegurando que los asentamientos judíos tanto del pasado y del presente, no ayudan a las FDI para defender el Estado de Israel, a la vez que reitera que la administración militar es una medida transitoria que terminará al finalizar la ocupación ${ }^{102}$.

Esas facultades que tiene el Gobierno Militar de restablecer la ley y el orden en los TO, no otorgan derechos para constituir un nuevo orden en la región. Es decir, en el momento de establecer los asentamientos judíos de manera permanente, conlleva a un cambio que no se corresponde con las medidas transitorias que se pueden tomar en el momento de la ocupación. Esto cambia la situación jurídica de los TO porque el derecho aplicable es el israelí, toda vez que los residentes judíos están sometidos a la jurisdicción de los tribunales de Israel. Esta situación genera un sistema jurídico dual, uno para la población palestina y otro para la población judía asentada en la región. Las medidas que modifican la estructura geográfica deben tener en cuenta la protección de los derechos humanos de la población palestina, pues los ciudadanos israelíes residentes en los asentamientos judíos gozan de bienes materiales, derechos políticos, económicos y sociales que son superiores a los de los residentes palestinos $\mathrm{TO}^{103}$.

La decisión final del TSI sobre los asentamientos judíos ha sido de abstención ante cualquier pronunciamiento que no tuviera un vínculo directo con la violación de los derechos humanos. Las peticiones no se presentaron por la violación a los derechos de propiedad de los residentes palestinos sino para determinar si los asentamientos eran legales o ilegales. La política del Estado de Israel de construir viviendas en territorios donde la población palestina ha hecho presencia histórica, desconociendo las obligaciones del Estado como parte del IV Convenio de Ginebra, muestra cómo en todos los años de ocupación el gobierno se aleja cada día más de las obligaciones de aplicar las disposiciones internacionales.

El sistema jurídico que estableció el Gobierno Militar en la Franja de Gaza y en Cisjordania, no es el mismo para la población de los asentamientos judíos creados en los TO. Estos se rigen por la legislación israelí lo que equivale a decir que Israel tiene jurisdicción más allá de sus fronteras ${ }^{104}$. El Knesset ha promulgado normas para los asentamientos judíos pero estas no aplican a la población palestina, lo que demuestra nuevamente la duplicidad jurídica en los TO. La aplicación de las normas

102 HCJ 4481/91 "Barguil v. Government of Israel", Disponible en: http://elyon1.court.gov.il/files_eng/91/810/044/Z01/91044810.z01.pdf [fecha de visita 3 de diciembre de 2015], párr. 2C.

103 HCJ 4481/91, p. 5.

104 ShaWAN (2003) 51. 
legales e institucionales en Cisjordania y en Gaza, no aplican de manera territorial sino a título personal.

Gar Yein Ng sotiene que "Judges are set apart as impartial and independent in constitucional theory to offset unjust laws being passed or unjust actions by goverment and administration" 105 . De manera que las acciones militares contrarias con la normativa internacional o las disposiciones constitucionales de Israel, tendrán que ser revisadas por un tribunal para evitar los abusos de autoridad en los TO. La ocupación israelí ha traído cambios negativos en la región de Palestina que muestran la duplicidad normativa entre la población israelí y la palestina; por consiguiente, es necesario hacer mención a la construcción del muro en Palestina autorizada en el gobierno de Ariel Sharón, en respuesta a los ataques contra la población israelí pero que sin duda constituyen un obstáculo más a un futuro proceso de Paz.

\section{9) LA CONSTRUCCión del MURO EN PALESTina}

En el mandato del Primer Ministro Ariel Sharon en el 2002, se autorizó la construcción de un muro que separa Israel de los $\mathrm{TO}^{106}$ evitando así la entrada de grupos armados que trasladan armas y artefactos utilizados para atentar contra la vida de la población israelí. Esta medida se tomó como algo temporal pero subsiste en la actualidad, obstaculizando las negociaciones de paz ${ }^{107}$. Así las cosas, la Corte Internacional de Justicia (en adelante, CIJ) en opinión consultiva se pronuncia sobre la ocupación Israelí de territorio palestino toda vez que este hecho tiene importancia jurídica internacional, afectando no solamente a las partes en la controversia sino a terceros Estados ${ }^{108}$. En el dictamen por la construcción del muro en territorio ocupado palestino, dispuso que era contrario al derecho internacional y estableció que trajo la destrucción de hogares, restricción de movimiento, pérdida de empresas agrícolas, y por eso se instó a Israel para buscar todas las formas necesarias de reparación de los daños ${ }^{109}$. Asimismo, tuvo en cuenta los aspectos considerados por el TSI

105 YeIN-NG, Gar (2007) Quality of Judicial Organization and Checks and Balances. Oxford: Intersentia, p.13.

106 Álvarez-Ossorio, Alvariño (2004) "El Muro de Separación y el futuro de Palestina". Real Instituto Elcano, No 126, p. 1.

107 En este caso se utilizará el término de "muro" empleado por la Corte Internacional de Justicia en la Opinión consultiva sobre las consecuencias de la construcción de un muro en territorio palestino.

108 Badia Martí, Anna (2005) "La opinión consultiva de la Corte Internacional de Justicia sobre las consecuencias jurídicas de la construcción de un muro en territorio palestino ocupado 9 de julio de 2004”. Revista Electrónica de Estudios Internacionales, Vol. 9, p. 2.

109 Legal Consequences of the Construction of a Wall in the Occupied Palestinian Territory, advisory Opinion, ICJ Reports 2004, párr. 152. Disponible en:

http://www.icj-cij.org/docket/files/131/1671.pdf?PHPSESSID=8ac6811457d65f3ff8b330c $888 \mathrm{e} 31 \mathrm{ab} 8$ 
en el caso Beit Sourik ${ }^{110}$ en la construcción del muro por necesidades militares, pero contrario a esto, la CIJ dispuso que la construcción del tramo del muro se dio por motivaciones políticas y no militares, porque la ruta de este pasa por los asentamientos judíos construidos en los $\mathrm{TO}^{111}$. No obstante, no dice nada relacionado con la construcción del muro por necesidad militar sino que simplemente señala los dańos ocasionados en virtud de las obligaciones del $\mathrm{DIH}^{112}$, concluyendo que el Estado de Israel no cumple porque el Convenio de La Haya de 1907 al ser norma consuetudinaria, es oponible a Israel aunque no haya dado su consentimiento. A su vez, considera aplicable el IV Convenio de Ginebra contrario al argumento de Israel que no es vinculante aunque es parte del mismo, porque solo se aplica en el caso de un Estado que ostenta legítima soberanía sobre el territorio que ocupa.

La CIJ señala el artículo 2 de la IV Convención de Ginebra, y para aplicarla es necesario que exista un conflicto armado con independencia del reconocimiento o no del estado de guerra, y que el conflicto haya surgido entre dos partes contratantes ${ }^{113}$. Establece la obligación del Estado de Israel de cumplir con las obligaciones de la IV Convención de Ginebra toda vez que la ratificó el 6 de julio de 1951, de la misma forma la orden No. 3 emitida por la autoridad israelí después de la ocupación militar de Cisjordania y Gaza en 1967, ratificando que el Tribunal Militar israelí debe aplicar las provisiones de la IV Convención de Ginebra de 1949, y cuando exista conflicto entre la orden y la IV Convención de Ginebra prevalecerá esta última ${ }^{114}$.

110 En el caso Beit Sourik se presentó una demanda ante el TSI contra la orden de embargo emitido por el Comandante de las Fuerzas de Defensa de Israel, para tomar posesión de parcelas de tierra en Cisjordania (denominada en Israel por su nombre histórico de Judea y Samaria) para la construcción de un tramo del muro en tierras de propiedad privada. La demanda se sustentaba en que la orden de confiscación de tierras era ilegal y por eso se debía anular o en su defecto, cambiar la ubicación de construcción del muro. El TSI estableció que las modificaciones realizadas por la potencia ocupante en territorio ocupado son para mantener el orden y la seguridad en la región, y por eso es importante la construcción de un muro que impida el paso de terroristas palestinos. No obstante, no dice nada en relación con los asentamientos judíos construidos dentro del territorio palestino, y el beneficio que la construcción del muro trae para estos. El TSI concluye que en Beit Sourik, la ventaja militar de la seguridad lograda con la construcción de un tramo del muro, no era proporcional el daño adicional que se causó a la población; por tanto, se recomendó construir rutas alternativas aunque esta medida redujera la seguridad en la región. Ver, HCJ 2056/2004, Beit Sourik, párr. 71

111 ICJ. 2004, párr. 120-121.

112 ICJ. 2004, párr. 89.

113 Palestina aceptó de manera unilateral el 7 de julio de 1982, la aplicación de la IV Convención de Ginebra.

114 ICJ. 2004, p. 41. 
Los asentamientos construidos por Israel en territorio palestino constituyen una violación a la IV Convención de Ginebra ${ }^{115}$ donde establece la prohibición del traslado forzoso, las medidas tomadas por la potencia ocupante que busquen alterar la vida del territorio ocupado, por ejemplo, el traslado de parte de su propia población dentro del territorio ocupado. En este mismo sentido, la CIJ dispuso que la construcción del muro constituya un riesgo a futuro de alteración de la composición demográfica del territorio ocupado palestino, porque esta demarcación no corresponde con la línea verde del Plan de la ONU para la partición de Palestina en 1947, aprobado en la resolución $181^{116}$, lo que en la práctica constituye una anexión. La construcción impide el ejercicio del pueblo palestino de su derecho a la autodeterminación ${ }^{117}$, constituyendo una violación de la obligación de Israel de respetar este derecho y condicionando futuras negociaciones de paz entre Israel y Palestina ${ }^{118}$. Entonces, determinó la obligación de Israel a cumplir con los derechos humanos, porque su protección no debe cesar en caso de conflicto armado y son aplicables a los actos de un Estado en el ejercicio de su jurisdicción fuera de su propio territorio $^{119}$. En el argumento de la CIJ sobre la aplicación de los tratados de derechos humanos fuera del territorio del Estado, se basa en que Israel ejerce la jurisdicción de los TO y por tanto, está obligado en su cumplimiento. Es importante anotar que Israel hace parte del Convenio internacional en la eliminación de todas las formas de discriminación racial, ratificado el 3 de enero de 1979 y el Convenio internacional de derechos civiles y políticos, ratificado el 3 de octubre de 1991.

Con la construcción del muro se está incumpliendo con las obligaciones que se tienen en DIH y el Derecho Internacional de los Derechos Humanos: la libertad de movimiento, derecho al trabajo, la salud, la educación y a un nivel de vida adecuado ${ }^{120}$. Al vulnerar el derecho al trabajo de la población palestina se están afectando otros derechos conexos a causa de la construcción del muro, con lo cual, Israel incumple con la obligación de potencia ocupante en la protección de los grupos humanos ${ }^{121}$. Frente al argumento de la construcción del muro en palestina en razón de

115 Artículo 49 (6). Ver, Kretzmer, David (2005) "The Advisory Opinion: The Light Treatment of International Humanitarian Law". The American Journal of International Law, Vol. 99, p. 91.

116 De Azcarate, Pablo (1968) Misión en Palestina. Madrid: Editorial Tecnos, S.A., pp. 11-12.

117 Díaz Barrado, Castor Miguel (2011) "La autodeterminación del pueblo palestino: la clave para la solución de los conflictos". En Vacas Fernández, Félix (director); Guerrero Fernán$\mathrm{dez}$, Alberto (coordinador): Palestina e Israel en el nuevo contexto interno e internacional. Getafe: Instituto de Estudios Internacionales y Europeos "Francisco de Vitoria”, p. 3.

118 ICJ. 2004, parr. 122-123.

119 ICJ. 2004, parr. 106.

120 ICJ. 2004, parr. 133-134.

121 Artículo 39- II. Medios de existencia. IV Convenio de Ginebra de 1949. Ver Orakhelashvili, Alexander (2006) "Legal Consequences of the Construction of a Wall in the Occupied 
la legítima defensa, la CIJ lo rechazó porque no cumple con lo dispuesto en la Carta de las Naciones Unidas, pues la amenaza no surge del ataque de otro Estado, sino de un territorio bajo control de Israel, por tanto, no es una justificación válida ${ }^{122}$, como tampoco se puede evidenciar los beneficios que esta construcción tiene para la población israelí, y que constituye el principal argumento del Estado ocupante ${ }^{123}$. La CIJ dispuso que Israel debía cesar en la construcción del muro, incluido los alrededores de Jerusalén, a cumplir con las obligaciones del DIH y del Derecho Internacional de los derechos humanos, a desmantelar las partes de la estructura del muro situado dentro de los TO, buscar la forma de compensar o indemnizar a todas las personas naturales o jurídicas; recordando que en el derecho internacional consuetudinario existe un principio que es de reparación, donde se busca suprimir mientras sea posible todos los actos ilegales y volver al momento anterior que estos se realizaron.

El Estado de Israel ignoró el dictamen e hizo las modificaciones de acuerdo con las disposiciones del TSI, donde tuvo en cuenta el cumplimiento de los requisitos de proporcionalidad dispuestos por este, cuando establece que los cambios serán necesarios en virtud de la necesidad militar ${ }^{124}$.

\section{CONCLUSIONES}

La aplicación del derecho internacional en los TO, no se puede decir que sea una práctica constante y consecuente, porque en ocasiones es imprecisa o muy restrictiva, en particular cuando están en juego los intereses del Estado de Israel. Al no existir una revisión judicial de las actividades militares en los TO, el control establecido por el TSI casi siempre se ha derivado de las reclamaciones que se presentan, y no por el control constitucional de la actuación del Gobierno Militar. Con lo cual, la situación de ocupación militar permite hacer cambios en la región ocupada sin que este tenga un cuestionamiento o un control. Se puede decir que hay avances en materia de protección de los derechos humanos en los TO, porque el TSI se ha pronunciado en algunos casos favoreciendo y reconociendo los abusos de la autoridad militar; no obstante, ha fracasado al permitir la

Palestinian Territory: Opinion and Reaction”. Journal of Conflict and Security Law, Vol. 11, p. 123

122 Legal Consequences of the Construction, parr. 142-143. Véase, Kretzmer (2005) 96. SсовBIE, Iain (2006) "Unchart (er) ed Waters? Consequences of the Advisory Opinion on the Legal Consequences of the Construction of a Wall in the Occupied Palestinian Territory for the Responsibility of the UN for Palestine". The European Journal of International Law, Vol. 16 , No 5 , p. 943.

123 ICJ. 2004, párr. 63.

124 HCJ 2056/2004, párr. 44. 
consolidación de un sistema legal dual, uno para la región palestina y otro para los asentamientos judíos.

El apoyo del gobierno de Israel en la construcción de nuevas viviendas en los TO, ha generado la creación de nuevas órdenes militares, que buscan proteger los intereses de la población judía pero van en detrimento de los derechos humanos de la población de los TO. Esta situación ha desvirtuado el papel del Gobierno Militar en la región, porque uno de los objetivos fundamentales de este, es restaurar, mantener el orden público y la seguridad en la región; algo que se consigue con la aplicación de las normas internacionales y el respeto por los principios del derecho internacional. Contrario a las medidas tomadas en la región, mientras el Estado de Israel apoye los asentamientos judíos y mantenga la ocupación militar, no se puede hablar de un desarrollo y autonomía de la población de los TO, ni tampoco de respeto por las obligaciones derivadas del derecho internacional humanitario.

\section{BIBLIOGRAFÍA CITADA}

\section{LIBROS}

Arai-Takahashi, Yutaka (2009) The Law of occupation: continuity and change of international Humanitarian Law, and its interaction with international Human Rights Law. California: Martinus Nijhoff, 760 pp.

Azoulay, Ariella; Ophir, Adi (2012) The one state-condition: Occupation and Democracy in Israel/Palestine. Standford California: Standford University Press, 344 pp.

Benvenisti, Eyal (1993) The international law of occupation. New Jersey: Princeton Universal Press, 241 pp.

Benvenisti, Eyal (1997) "Judicial Review of Administrative Action in the Territories Occupied in 1967". En Itzhak, Zamir; Zysblat, Allen: Public Law in Israel. Oxford: Clarendon Press, 464 pp.

Benvenisti, Meron (1984) The West Bank Database Project: A survey of Israel's policies. Washington: American Enterprise Institute for Public Policy Research, 97 pp.

Boyle, Francis Anthony (2003) Palestine, Palestinians and International Law. Michigan: Clarity Press, 205 pp.

CoHen, Esther (1985) Human Rights in the Israel-Occupied Territories 1967-1982. Manchester: Manchester University Press, 322 pp.

De Azcarate, Pablo (1968) Misión en Palestina. Madrid: Editorial Tecnos, S.A., 229 pp. 
Díaz Barrado, Castor Miguel (2011) "La autodeterminación del pueblo palestino: la clave para la solución de los conflictos". En Vacas Fernández, Félix (director); Guerrero Fernández, Alberto (coordinador): Palestina e Israel en el nuevo contexto interno e internacional. Getafe: Instituto de Estudios Internacionales y Europeos "Francisco de Vitoria", 111 pp.

Dinstein, Yoram (2009) The International Law of belligerent occupation. Cambridge: University Press, $336 \mathrm{pp}$.

Fernández Gómez, Manuel; Peco Yeste, Miguel (2003) El Conflicto Palestino-Israelí. Madrid: Instituto de Estudios Internacionales y Europeos "Francisco Vitoria", 127 pp.

Fort Navarro, Albert; Martínez Ibáñez, Enrique (2002) El conflicto Palestino-Israeli: un recorrido histórico para comprender el presente. Valencia: Diálogo, 155 pp.

Institute for Palentine Studies (1984) The Karp report: An Israeli government inquiry into settler violence against Palestinians on the West Bank. Washington: Institute for Palestine Studies, $80 \mathrm{pp}$.

Jacoby, Tami Amanda; Sasley, Brent E. (2002) Redefining Security in the Middle East. Canada: Manchester University Press, 176 pp.

Peleg, Ilan (1995) Human rights in the West Bank and Gaza. Legacy and Politics. $1^{\circ}$ edition. New York: Syracuse University Press, $191 \mathrm{pp}$.

Playfair, Enma (1992) International law and the Administration of Occupied Territories. Oxford: Clarendon Press, 534 pp.

Rubinstein, Amnon (1996) The Constitutional Law of the State of Israel. $5^{\mathrm{a}}$ edition. Tel Aviv: Shoken, $1191 \mathrm{pp}$.

Shamgar, Meir (1982) "Legal Concepts and Problems of the Israeli Military Government-The Initial Stage". En Shamgar, Meir (editor): Military government in the territories administered by Israel 19671980: the legal aspects. Jerusalem: Alpha Press, pp. 13-60.

Shawan, Usahma (2003) Public Administration in Palestine: past and present. Oxford: University Press of America, 140 pp.

Shemader, Raja (1985) Occupier's Law: Israel and the West Bank. $1^{\circ}$ Edition. Washington: Institute for Palestine Studies, $212 \mathrm{pp}$.

Shetreet, Shimon (1994) Justice in Israel: A Study of the Israeli Judiciary. Boston: Martinus Nijhoff Publishers, 576 pp.

Thürer, D. (2011) International Humanitarian Law: A Unique Regime. Collected Courses of the Hague Academy of International Law, Vol. 338. Brill Nijhoff: Hague Academy of International Law, 370 pp.

Voorhoeve, Joris (2007) From War to the Rule of Law: Peacebuilding after violent conflicts. Amsterdam: University Press Amsterdam, 203 pp.

Yein-NG, Gar (2007) Quality of Judicial Organisation and Checks and Balances. Oxford: Intersentia, 428 pp.

Zamir, Itzhak; Zysblat, Allen (1996) Public Law in Israel. Oxford: Clarendon Press, 464 pp. 


\section{ARTículos CITAdos}

Allan, Gerson (1973) “Trustee-Occupant: The Legal Status of Israel's Presence in the West Bank". Harvard International Law Journal, Vol. 14, pp. 1-49.

Badia Martí, Anna (2005) "La opinión consultiva de la Corte Internacional de Justicia sobre las consecuencias jurídicas de la construcción de un muro en territorio palestino ocupado 9 de julio de 2004". Revista Electrónica de Estudios Internacionales, Vol. 9, pp. $1-23$.

Bar-YaAkov, Nissim (1990) "The Applicability of the Law of war to Judea and Samaria (The West Bank) and to the Gaza Strip". Israel Law Review, Vol. 24, pp. 485-506.

Cohen, Esther (1985-1986) "Justice for Occupied Territory? The Israeli High Court of Justice Paradigm”. Columbia Journal Transnational Law, Vol. 24, pp. 471-508.

Droege, Cordula (2007) "The Interplay between international humanitarian law and international human rights law in situations of armed conflict". Israel Law Review, Vol. 40, N² 2, pp. 310-355.

Drori, Moshe (1977) "Second Municipal Elections in Judea and Samaria under Israel Administration: Legislative Changes". Israel Law Review, Vol. 12, pp. 526-540.

Drori, Moshe, (1978).”The legal system in Judea and Samaria: a review of the previous decade with a glance of the future". Israel Yearbook on Human Rights, Vol. 8, pp. 144-177.

Grinberg, Lev (2008) "El 'régimen dual' en Israel desde 1967". Araucaria: Revista Iberoamericana de Filosofía, Politica y Humanidades, $\mathrm{N}^{\circ} 19$, primer semestre, pp. 124-151.

KaraYanni, Michael M. (2014) "Access to Justice Ascends to International Civil Litigation: The Case of Palestinian Plaintiffs before Israeli Courts". Civil Justice Quarterly, Vol. 33, N 1, pp. 41-75.

Koutroulis, Vaios (2002) "La aplicación del derecho internacional humanitario y el derecho internacional de los derechos humanos en situaciones de ocupación prolongada: ¿solo cuestión de tiempo?”. International Review of the Red Cross, No 885, pp. 1-45.

Kretzmer, David (2005) "The Advisory Opinion: The Light Treatment of International Humanitarian Law". The American Journal of International Law, Vol. 99, pp. 88-102.

LAPIDOTH, Ruth (1990) "International Law within the Israel Legal System". Israel Law Review, Vol. 24, pp. 451-484.

Orakhelashvili, Alexander (2006) "Legal Consequences of the Construction of a Wall in the Occupied Palestinian Territory: Opinion and Reaction". Journal of Conflict and Security Law, Vol. 11, pp. 119-139. 
Roberts, Adam (1990) "Prolonged military occupation: the Israelioccupied territories since 1967". The American Journal International Law, Vol. 84, pp. 44-103.

Roberts, Adam (2006) "Transformative military occupation: applying the laws of ward and human rights". The American Journal International Law, Vol. 100, pp. 580-622.

Rubinstein, Amnon (1988) "The changing status of the "territories" (West Bank and Gaza): From scrow to legal mongrel". Tel Aviv University Studies in Law, Vol. 8, pp. 59-80.

SABRI, Nidal (1995) "The Effects of Taxes Imposed on the Population of the Occupied Palestinian Territories". Paper presented at the Seminar on Living Conditions of the Palestinian People. Vienna: Habitat.

Sсоввіе, Iain (2006) "Unchart (er) ed Waters? Consequences of the Advisory Opinion on the Legal Consequences of the Construction of a Wall in the Occupied Palestinian Territory for the Responsibility of the UN for Palestine". The European Journal of International Law, Vol. 16, No 5, pp. 941-961.

Shamgar, Meir (1971) "The Observance of International Law in the Administered Territories". Israel Yearbook on Human Rights, Vol. 1, pp. 262-277.

Shetreet, Shimon (1986) "Limmits and promises of International norms and procedure for the Protection of Human Rights". En Goldstein, Stephen: Israeli Reports to the International 12th Congress of law. Jerusalem: Harry Sacher Institute for Legislative Research and Comparative Law, pp. 1-103.

Singer, Joel (1982) "The establishment of a civil administration in the areas administered by Israel". Israel Yearbook on Human Rights, Vol. 12, pp. 259-289.

Yiftachel, Oren (1997) "Israel society and jewish-palestinian reconciliation: "Ethnocracy' and its territorial contradictions". The Middle East Journal, Vol. 51, N 4, Autumn, pp. 505-519.

\section{INFORMES DE ORGANIZACIONES NO GUBERNAMENTALES}

Amnistia Internacional (1991) Israel and the occupied territories: the military justice system. New York: Amnesty international, p. 17.

B" tselem (1990) The Military Judicial System in the West Bank- Follow up Report.

Comité Contra la tortura (2009) CAT/C/ISR/CO/4, 23 de junio de 2009, Disponible en: http://www.acnur.org/biblioteca/pdf/7944.pdf [fecha de visita: 16 de julio de 2015]. 


\section{PÁGinas Web CONSUltadas}

The situation in the Middle East, AG Res. 32/20 noviembre 25 de 1977. http://www.un.org/es/documents/ag/res/32/ares32.htm [fecha de visita: 16 de julio de 2015].

Agreed documents on movement and access from and to Gaza (2005). Disponible en:

http://www.mfa.gov.il/mfa/foreignpolicy/peace/mfadocuments/pages/ agreed $\% 20$ documents $\% 20$ on $\% 20$ movement $\% 20$ and $\% 20$ access $\% 20$ from $\% 20$ and $\% 20$ to $\% 20$ gaza $\% 2015$-nov-2005.aspx

Ley Básica: Jerusalén, Capital de Israel. 30 de julio de 1980. Disponible en:

http://www.mfa.gov.il/MFA/MFAArchive/1980_1989/Basic+Law+Jerusalem-+Capital+of+Israel.htm [fecha de visita: 28 de julio de 2014]

Declaration concerning the Laws and Customs of War. Brussels, 27 August, 1874, http://www.icrc.org/ihl.nsf/ FULL/135? OpenDocument [fecha de visita: 29 de julio de 2014].

\section{JURISPRUDENCIA CITADA}

HCJ 69/81 "Abu Aita et al. v. The Regional Commander of Judea and Samaria”, párr. 53(c) p. 146. Disponible en: http://elyon1.court.gov. il/files_eng/81/690/000/Z01/81000690.z01.htm

[fecha de visita: 3 de diciembre de 2015].

HCJ 393/82 "Jamait Askan et al. v. IDF Commander of Judea and Samaria". Disponible en: http://http://hamoked.org/items/160_eng. pdf [fecha de visita: 3 de diciembre de 2015].

HCJ 785/87 "Abd Al Nasser Al Azis v. Commander of IDF forces in the West Bank". Disponible en: http://elyon1.court.gov.il/files_ eng/87/850/007/Z01/87007850.z01.htm [fecha de visita: 3 de diciembre de 2015].

HCJ 4481/91 "Barguil v. Government of Israel", Disponible en: http:// elyon 1.court.gov.il/files_eng/91/810/044/Z01/91044810.z01.htm [fecha de visita: 3 de diciembre de 2015]. 